\title{
How concentrated is crime at places? A systematic review from 1970 to 2015
}

\author{
YongJei Lee ${ }^{1}$, John E. Eck ${ }^{2 *}$, SooHyun $\mathrm{O}^{2}$ and Natalie N. Martinez ${ }^{2}$
}

\begin{abstract}
Background: Despite the increasing awareness and interests about the importance of crime concentration at places, scholars have not comprehensively synthesized the body of evidence related to this thesis. We conduct a systematic review and meta-analysis of the evidence that crime is concentrated among places.

Methods: We identified 44 studies that empirically examined crime concentration at place and provided quantitative information sufficient for analysis. We organized data using visual binning and fitted logarithmic curves to the median values of the bins. We examine concentration in two conditions: when all places are studied (prevalence), and when only places with at least one crime are studied (frequency).

Results: We find that crime is concentrated at a relatively few places in both conditions. We also compared concentration for calls for services to reported crime incidents. Calls for services appear more concentrated than crime at places. Because there are several ways place is defined, we compared different units of analysis. Crime is more concentrated at addresses than other units, including street segments. We compared crime concentration over time and found less concentration in 2000s compared to 1980s and 1990s. We also compared crime concentration between U.S. and non-U.S. countries and found more concentration in U.S. Finally, violent crime is more concentrated than property crime.

Conclusions: Though we systematically reviewed a comprehensive list of studies, summarizing this literature is problematic. Not only should more systematic reviews be conducted as more research becomes available, but future inquiries should examine other ways of summarizing these studies that could challenge our findings.
\end{abstract}

Keywords: Concentration of crime, Place, Systematic review, Meta-analysis, Visual binning

\section{Background}

At the end of the 1980s, Sherman et al. (1989) argued that a small proportion of addresses in a city were the sites of most crime, and that focusing police resources on these high-crime addresses would be beneficial for crime prevention. Their influential findings opened a new avenue for researchers and practitioners, since most past studies of the geography of crime had focused on neighborhoods or larger areas. Shortly after, Spelman and Eck (1989) compared the concentration of crime among places, offenders, and victims, and suggested that crime is more likely to concentrate at places rather than offenders or

\footnotetext{
*Correspondence: john.eck@uc.edu

${ }^{2}$ School of Criminal Justice, University of Cincinnati, Cincinnati, $\mathrm{OH} 45221$, USA

Full list of author information is available at the end of the article
}

victims. Since the late 1980s, followers of this line of research have provided empirical evidence of place concentration using various measures of crime, focusing on different crime places and geographic units of analysis, and employing different time windows of the dataset.

For example, Weisburd and his coauthors (2004) found that the crime reduction in Seattle during the 1990s was mostly due to crime declines in a small group of street segments. In a series of meta-analysis of crime hot spots patrol studies, Braga $(2001,2005)$ and Braga et al. (2014) provided more evidence of crime concentration at places, and that when police focus their patrols at these highcrime locations they can create significant reductions in crime. The concentration of crime is so common that Wilcox and Eck (2011) call it the "Iron Law of Crime Concentration," and Weisburd (2015) calls it the "Law of 
Crime Concentration." In fact, Weisburd claims that this concentration is so regular that a given percent of the worst crime afflicted places account for a fixed percent of the crime in almost every city.

Despite this increasing awareness and interests about the importance of crime concentration at places, scholars have not comprehensively synthesized the body of evidence related to this thesis. Such a review is important because it can help determine if crime concentration is as lawlike as Weisburd suggests (2015). ${ }^{1}$ A review would also provide evidence for how much variation in concentration there is in the literature. And if there is considerable variation, the types of factors that might influence the variation in crime concentration would be fruitful for future place-based crime research to be considered. Finally, as "place" is defined in several ways-as addresses (e.g., inside bars or business stores), as street segments (both sides of a street from corner to corner), and as tiny areas (grid cells of several hundred feet on a side) ${ }^{2}-$ a systematic review could help indicate whether this operationalization of "place" influences the concentration of crime.

In this paper, we describe a systematic review and meta-analysis of the literature describing how concentrated crime is in small geographic units known as places. ${ }^{3}$ In the next section, we describe the literature search strategy we followed: the types of literature we included in our review, how we extracted data from the literature, and how we synthesized various findings using the visual binning method. The third section provides the results of our analysis of this literature. Here we give estimates of the level of concentration of crime at places and examine how this changes as methods change and as crime types are varied. The last section draws conclusions from these results and discusses possible future research and policy implications.

\section{Methods}

\section{Criteria for inclusion and exclusion}

Our goal is to determine the concentration of crime at places based on the research that has been conducted. We need quantitative information that can describe the distribution of crime across a sample of places. To

\footnotetext{
${ }^{1}$ Weisburd (2015a, b) claims the Law of crime concentration at place which suggests that certain percentage of places accounts for a fixed percentage of crime (e.g., $5 \%$ of street segments accounts for $50 \%$ of crime across different cities.).

${ }^{2}$ The geographic units of analysis we examined here are based on the U.S. street-line system

${ }^{3}$ These places include both propriety places (e.g., land parcels with a single legal owner. Typically addresses) and proximal places (short strips of adjacent proprietary places. Typically, these are street segments.) suggested by Madensen and Eck (2008)
}

achieve this, we require specific information describing crime at place concentration, which are reflected in our three criteria for inclusion in our analysis. First, the study must be written in English. ${ }^{4}$ Second, the study had to include empirical data to draw their findings, so we can either access to the study's original dataset or retrieve relevant statistics from the study. Third, the study must provide statistics on the percentage of places (X percent) in its sample and percentage of crimes ( $\mathrm{Y}$ percent) associated with those places. We use the combinations of these $\mathrm{X}-\mathrm{Y}$ percentages as ordered pairs to plot points on the concentration curve. For example, Sherman and his coauthors (1989 provided a cumulative distribution of 323,979 calls to police over all 115,000 addresses (and intersections) in Minneapolis over 1 year. In Table 1 of their study, each of the 16 rows provides the percentage of crime explained by the percentage of addresses, thus it is possible to retrieve and record these $16 \mathrm{X}-\mathrm{Y}$ points into our database.

Since insufficient $\mathrm{X}-\mathrm{Y}$ points may not reliably represent the distribution of crime across the geographic units of the study-a single $\mathrm{X}-\mathrm{Y}$ point does not reliably represent the place-crime distribution of the study-we applied another criteria to filter out the studies with insufficient $\mathrm{X}-\mathrm{Y}$ points. Specifically, in addition to the points where the percent of places is $100 \%$ or the percent of crimes is $100 \%$, relevant studies must supply at least two $\mathrm{X}-\mathrm{Y}$ ordered pairs to represent the place-crime distribution of the data.

\section{Data sources and search strategy}

We searched empirical studies addressing the concentration of crime at places in journal articles, academic institutions, crime analysts, and industry. We searched for relevant literature in ProQuest, EBSCO, Google Scholar, and Criminal Justice Abstract, using the keywords as follows: Hot spot, Crime place, Crime clusters, Crime displacement, Place-oriented interventions, High crime areas, and High crime locations. ${ }^{5}$ We identified further articles and reports from the bibliography sections of relevant studies, comments, and books. If we found new keywords (e.g., problematic places, risky facility, place based crime) during this process, we conducted another round of online search using the new

\footnotetext{
${ }^{4}$ Given the history of crime and geography in criminology (e.g., Quetelet), searching and reviewing studies written in English only may limit our understanding on the concentration of crime phenomenon. We encourage future studies to consider reviewing non-English written articles in this line of research.

${ }^{5}$ Here, we confirm that the studies that can be retrieved by using other sub-keywords, such as micro-place and micro area, were already retrieved by using these major keywords.
} 
Table 1 Characteristics of the studies and X-Y pairs identified and analyzed

\begin{tabular}{|c|c|c|c|c|}
\hline \multirow[t]{2}{*}{ Characteristics } & \multicolumn{2}{|l|}{ Prevalence } & \multicolumn{2}{|l|}{ Frequency } \\
\hline & $\begin{array}{l}\text { Number } \\
\text { of studies }\end{array}$ & $\begin{array}{l}\text { Number of } \\
X-Y \text { pairs }\end{array}$ & $\begin{array}{l}\text { Number } \\
\text { of studies }\end{array}$ & $\begin{array}{l}\text { Number of } \\
X-Y \text { pairs }\end{array}$ \\
\hline
\end{tabular}

\begin{tabular}{|c|c|c|c|c|}
\hline \multicolumn{5}{|l|}{ Year or report } \\
\hline 1971-1979 & 1 & 9 & 1 & 8 \\
\hline 1980-1989 & 3 & 83 & 3 & 74 \\
\hline 1990-1999 & 3 & 35 & 3 & 32 \\
\hline 2000-2009 & 6 & 100 & 4 & 77 \\
\hline 2010-2015 & 13 & 201 & 8 & 119 \\
\hline \multicolumn{5}{|c|}{ Measures of crime } \\
\hline Crime incident & 24 & 393 & 17 & 277 \\
\hline Calls for service & 2 & 35 & 2 & 33 \\
\hline \multicolumn{5}{|l|}{ Geographic unit ${ }^{\mathrm{a}}$} \\
\hline $\begin{array}{l}\text { Address (and } \\
\text { intersection) }\end{array}$ & 3 & 54 & 3 & 49 \\
\hline Household & 8 & 127 & 9 & 119 \\
\hline Segment & 13 & 196 & 5 & 105 \\
\hline $\begin{array}{l}\text { Area (parks and } \\
\text { buffers) }\end{array}$ & 1 & 12 & - & - \\
\hline \multicolumn{5}{|l|}{ Type of crime ${ }^{b}$} \\
\hline Violent & 6 & 55 & 4 & 25 \\
\hline Property & 6 & 82 & 6 & 75 \\
\hline \multicolumn{5}{|c|}{ Country of dataset } \\
\hline United States & 17 & 233 & 9 & 124 \\
\hline Non-U.S. & 9 & 195 & 10 & 186 \\
\hline \multicolumn{5}{|l|}{ Total } \\
\hline Studies analyzed & 26 & 428 & 19 & 310 \\
\hline $\begin{array}{l}\text { (Studies identi- } \\
\text { fied) }\end{array}$ & (44) & (489) & (20) & (316) \\
\hline
\end{tabular}

a We dropped facility-specific studies and their $X-Y$ pairs in our analysis because these studies were too narrowly focused on the subset of a population data (e.g., bars, business places)

b Non-violent and non-property crime studies are not included in this category because we could not categorize these types of crime (e.g., juvenile crime, calls for services, and non-categorized crime)

keyword, which is an iterative search process rather than a sequential process. Though we identified a number of studies that examined specific facilities (Eck et al. 2007) we did not include them in this study as these studies are unlike most of the relevant literature: they focus on a single type of place (e.g., only bars, or only apartment buildings) whereas most place studies examine heterogeneous places. ${ }^{6}$ We presented an early version of this study at the 2015 Environmental Criminology and Crime Analysis international symposium in Christchurch, New Zealand and at the 71st

\footnotetext{
${ }^{6}$ We only excluded the studies that had focused on the homogeneous type of facility. If a study included various types of facility as a subset of street address places, we included it in our review study.
}

Annual Conference of the American Society of Criminology at Washington, DC and asked attendees if they knew of any gaps in our literature. ${ }^{7}$

Finally, we identified 44 studies with one or more $\mathrm{X}-\mathrm{Y}$ points. This yielded $489 \mathrm{X}-\mathrm{Y}$ ordered pair points. ${ }^{8}$ But only 26 studies had two or more ordered pairs, so we analyzed the 428 points from these studies. ${ }^{9}$

\section{Coding protocol}

Our comparative analysis of crime concentration at place has no precedent in the literature. Conventional metaanalyses calculate a variety of statistics including t-statistics, estimated coefficients, standard errors, and confidence intervals and then weight the data points to compensate for uncertainty in the data (Mulrow and Oxman 1997; Higgins and Green 2011). However, because we used actual values of $\mathrm{X}-\mathrm{Y}$ ordered pairs to calculate the effect size between place and crime rather than estimated coefficients (as is standard in meta-analysis), it is unclear if weights improve the validity of our analysis. As our test of this indicated that weights were not helpful, we did not use them. ${ }^{10}$

We recorded the raw values of $\mathrm{X}-\mathrm{Y}$ ordered pairs for each study in two different ways. We first recorded $\mathrm{X}-\mathrm{Y}$ values based on the population of places. In Sherman et al. (1989), for example, 3.3\% of all the addresses in Minneapolis accounted for $50 \%$ crime and $50 \%$ of all addresses accounted for all crimes, which indicates the prevalence of crime for this city. So we adopted a term 'prevalence' to describe this type of $\mathrm{X}-\mathrm{Y}$ points.

However, if the study only describes places with at least one crime event, rather than entire population of places, we calculated the $\mathrm{X}$ based on the number of geographic units where crime had happened before. The value of this approach is that it provides the information as to how repeatedly a place suffers from crime. When we only use data of this sort, we call this an analysis of crime

\footnotetext{
${ }^{7}$ Given these limited databases and keywords we employed in this review study, there is a possibility that we may have missed some studies that contain relevant information. Therefore, future researchers who are interested in and planning to replicate this review study may want to include more comprehensive list of databases and keywords.

${ }^{8}$ We marked these studies with small cross symbol $\left({ }^{\dagger}\right)$ in the References.

${ }^{9}$ We marked these studies with small asterisk symbol (") in the References.

${ }^{10}$ We tested whether any significant difference would be found by weighting $\mathrm{X}-\mathrm{Y}$ points by the study's sample size (i.e., the number of places that each study had used to conduct statistical analyses). We used the study's sample size $(w)$ to weight $Y$ value of each point within each bin $(i)$, then calculated the weighted median $\left(\widetilde{w y}_{i}\right)$ to represent the weighted central tendency of each bin. We did not find any substantiate difference in the findings with weighted points compared to the findings with un-weighted points (see Appendix 1).
} 
"frequency". Because frequency ordered pairs were only available for some studies, we calculated both types of $\mathrm{X}-\mathrm{Y}$ points and recorded them in our database when it was possible. ${ }^{11}$

We coded the year of publication of the studies we reviewed. Between 1970 to 2015, the number of studies we reviewed has doubled for every decade. We also coded the geographic unit of analysis (e.g., address, street segment, block, block-group, census tract, neighborhood, county), ${ }^{12}$ measures of crime (e.g., calls for service, incident report, survey incident), and types of crime. Table 1 shows the summary characteristics of the studies we reviewed in this paper.

\section{Synthesis of evidence}

In order to answer the question "how crime is concentrated (or distributed) among places", we estimate the cumulative distribution of crime using visual binning tool in SPSS 21. Each bin on the horizontal axis represents a $1 \%$ interval over the range from 0 to $100 \%$ of the places arrayed from places with the most crimes to places with zero crimes (i.e., the first bin contains the most crime afflicted $1 \%$ of the places and the last bin contains $1 \%$ of the places, all of which have no crimes in the prevalence data). We then calculate the median values of $Y$ for each bin. We used this technique for two specific reasons. First, we assumed that $Y$ values within each $1 \%$ range bin on the horizontal axis vary, so we needed a measure of the central tendency of each $1 \%$ bin. Second, we chose the median as a representative statistic for each bin to remedy possibly skewed distributions of $\mathrm{Y}$ values in each bin. Figure 1 summarizes our visual binning process to draw cumulative distribution curves.

After a tabulation of median values of each bin, we estimate the cumulative curve by interpolating the median values. One can use various equation functions to fit the cumulative curve through these median points. We used the logarithmic and the power law functions as possible candidates to fit our lines. We used these since both functions are mathematically connected with each other: power-law behavior in either nature or

\footnotetext{
11 Just to clarify, the term 'prevalence' is connected to 'incidence' which measures the number of crimes per unit of population (Farrington 2015; Rocque et al. 2015; Tillman 1987), while 'frequency' is connected to 'concentration' which is the number of victimizations among victims (Osborn and Tseloni 1998; Trickett et al. 1992; Trickett et al. 1995).

12 We coded the studies with block, block-group, census tract, neighborhood, and county in our database, even if these studies were not reviewed after we filtered out the studies with a single $\mathrm{X}-\mathrm{Y}$ paired order.
}

social systems can be often transformed into a logarithmic scale for easier understanding on the phenomenon (Newman 2005).

To determine which function would produce a better fit, we compared their R-squared. Though this statistic is high for both functions, the R-squared for the logarithmic function is greater (see panel D in Fig. 1). Therefore, we used it to estimate the distribution curve between the cumulative percentage of (binned) place and crime. We selected only a single functional form to use throughout the analysis because we wanted to have a common standard metric for our comparisons that was simple to interpret. Further, as we anticipated comparing place concentration to victim and offender concentrations (see Eck et al. in this issue) we did not want to introduce variation in functional form.

\section{Results}

We examine the distribution of crime across places using both the prevalence and frequency data. Then we examine how concentration is influenced by the way crime is measured, the geographic unit of analysis, and the type of crime.

\section{Prevalence and frequency}

We use 26 studies with $428 \mathrm{X}-\mathrm{Y}$ points to estimate the prevalence curve, and 19 studies with 310 points to estimate the frequency curve. We fit both lines through the median values of each bin (using the logarithmic function) as illustrated in Fig. 2. The solid line is the estimated distribution of crime among all places (prevalence), while the shaded line is the estimated curve from places where crime had happened before (frequency). The R-squared values show that prevalence points are more widely dispersed around its line compared to frequency points, but both models fit well. In both cases, however, the fitted curve appears to be a better summary of the points at the far left (roughly the top $10 \%$ of the places) than further right. The frequency curve is a particularly poor fit after the top $50 \%$ of the places. This is unfortunate from the point of view of summarizing the data, but from a practical perspective it probably is not critical. This is because most applications of these data are concerned with the very worst places, and the curves fit the points well in that range.

In the prevalence curve, top $10 \%$ of serious crime places accounts for $63 \%$ of crime, while top $10 \%$ in the frequency curve explains $43 \%$ of crime. This difference in concentration is mostly, though not entirely, due to the fact most places have no crime. The estimated coefficient of each curve shows how fast, on average, the curve approaches the ceiling of the vertical axis $(\mathrm{Y}=100 \%)$ given marginal increase $(1 \%)$ in the $\mathrm{X}$ 


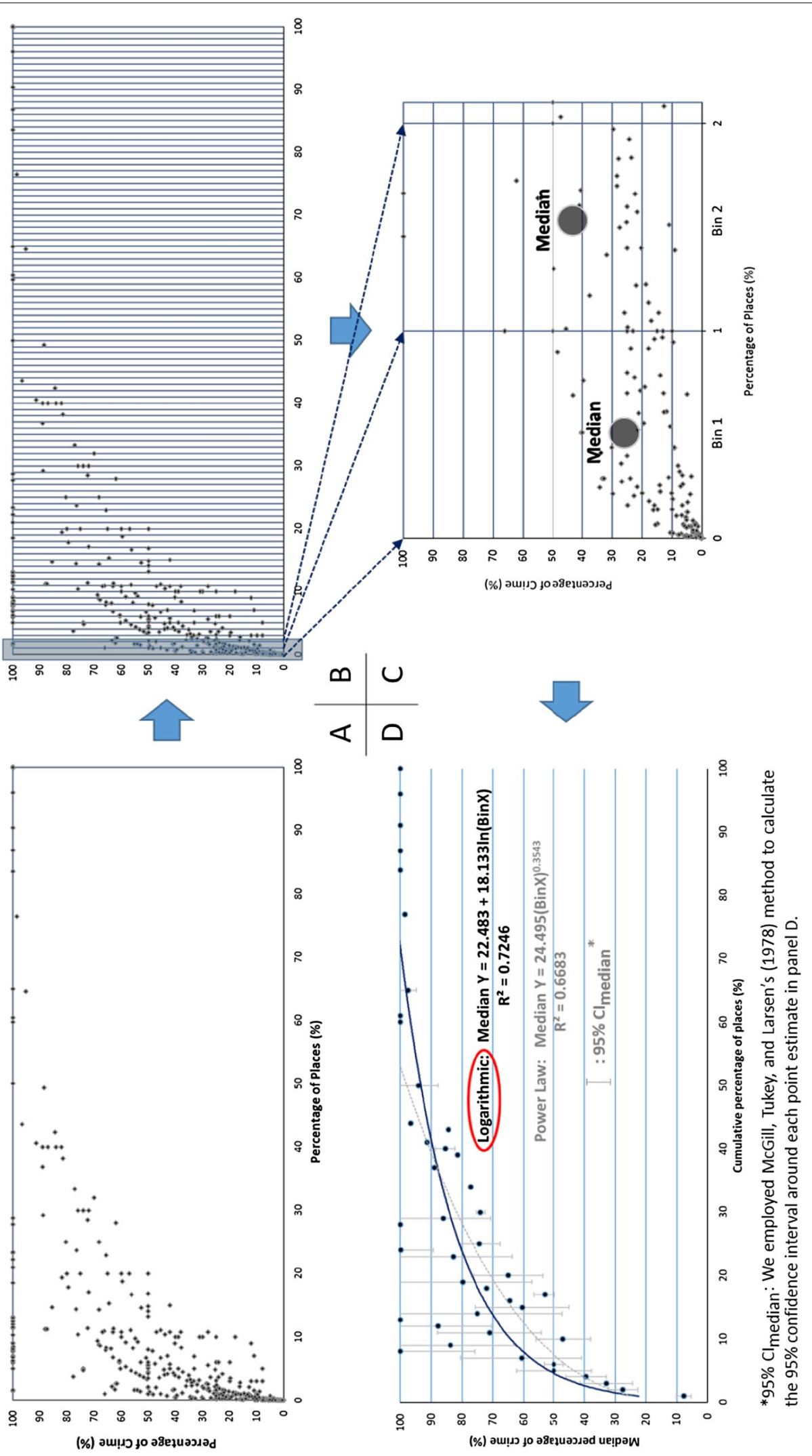

Fig. 1 A transformation procedure from empirical raw $X-Y$ ordered pairs to median values of each bin as effect size and curve estimation 


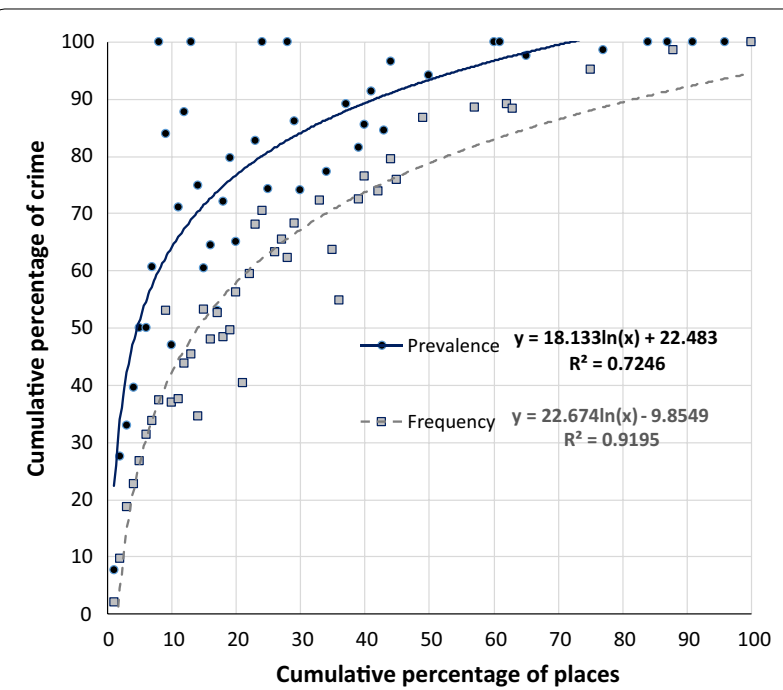

Fig. 2 Estimated distributions of crime at place between prevalence and frequency schema

value. ${ }^{13}$ Though the estimated coefficient of the frequency curve is significantly greater than estimated coefficient of the prevalence curve, prevalence curve reaches to the vertical ceiling faster than the frequency curve. ${ }^{14}$ This difference is primarily due to the intercept values in each model. The intercept value of the prevalence curve is over three times greater than the absolute value of the intercept of the frequency curve. The negative value of the frequency intercept has no theoretic

\footnotetext{
${ }^{13}$ Suppose we subtract the second reduced form equation from the first one.

$$
\begin{aligned}
& y+\Delta y=\beta_{0}+\beta_{1} \log (x+\Delta x)+e \\
& y=\beta_{0}+\beta_{1} \log x+e
\end{aligned}
$$$$
\text { then, }
$$$$
\Delta y=\beta_{1} \log \left(1+\frac{\Delta x}{x}\right)
$$

$$
\begin{aligned}
& \text { where } \frac{\Delta x}{\mathrm{x}} \approx \frac{1}{\mathrm{x}} \\
& \text { We can rewrite the Eq. (3) as, } \\
& \Delta y=\beta_{1} \frac{1}{x}
\end{aligned}
$$

and multiplying both side by 100 gives,

$$
\begin{aligned}
& 100 \cdot \Delta y=\beta_{1}\left(\frac{1}{x} \times 100\right)=\beta_{1} \Delta x \\
& \therefore \Delta y=\frac{\beta_{1}}{100} \Delta x
\end{aligned}
$$

Therefore, $1 \%$ increase in $\mathrm{x}$ will result in $\frac{\beta_{1}}{100}$ percentage change in $\mathrm{y}$.

${ }^{14}$ In Appendix 3, we provide the estimated coefficients and summary statistics of all models specifications in this paper.
}

interpretation, and is an indicator that the logarithmic function is less than ideal despite its better fit.

These results shed some light on Weisburd's (2015) conjecture, the Law of Crime Concentration-that a fixed percent of the places will almost always be the sites for a fixed large proportion of the crime. For both the prevalence and frequency curves, the dispersion of points around the fitted curves is very small on the left and wide on the right. So data fit quite well in the range of values for percent of places that are relevant for Weisburd's conjecture (e.g., below 10\%). Though these results are supportive, we must be cautious in interpreting these data. The binning process we used reduces the variation. So it is possible that this nice fit is due to our methods, rather than due to the law Weisburd imagines.

\section{Measures of crime}

Since researchers have extensively used calls for services (CFS) to police as a proxy for measuring crime (e.g., Sherman et al. 1989; Sherman 1995; Lum 2003; Weisburd et al. 2006), we wanted to see if studies using crime incident data systematically displayed more or less concentration than studies using CFS data.

We estimate both prevalence and frequency curves by different measures of crime. Among 26 studies we reviewed, two studies used CFS to measure crime while 24 studies used crime incident data. The estimated curves are shown in Fig. 3. CFS are more concentrated at place than actual number of incidents. More specifically, the estimated difference between CFS and crime incidents at the $10 \%$ bin is about $10 \%$. This difference increases when comparing frequency curves. The worst $10 \%$ of the places had $52 \%$ of CFS but only $40 \%$ of crime incidents.

These consistent findings across prevalence and frequency schema raise two important points. First, on average, CFS are more concentrated at place than crime incidents. Thus findings and results in the previous literature based on CFS as measures of crime may be biased upward. Second, researchers who employed CFS as measures of crime may have overlooked the fundamental difference between the characteristics of CFS and crime. Specifically, some researchers believe CFS is a good proxy for crime since CFS occurs with greater frequency (Andresen 2006; Phillips and Brown 1998). However, CFS can include numerous non-crime events ranging from requests from people suffering from mental illness, reports of suspicious activity, vehicular traffic incidents, and so forth. Perhaps the difference between the two curves could be due to a function of 'social efficacy'-the ability to deal with problems yourself. In Appendix 2, we give an explanation about how CFS as a proxy for crime could contaminate research and findings. 

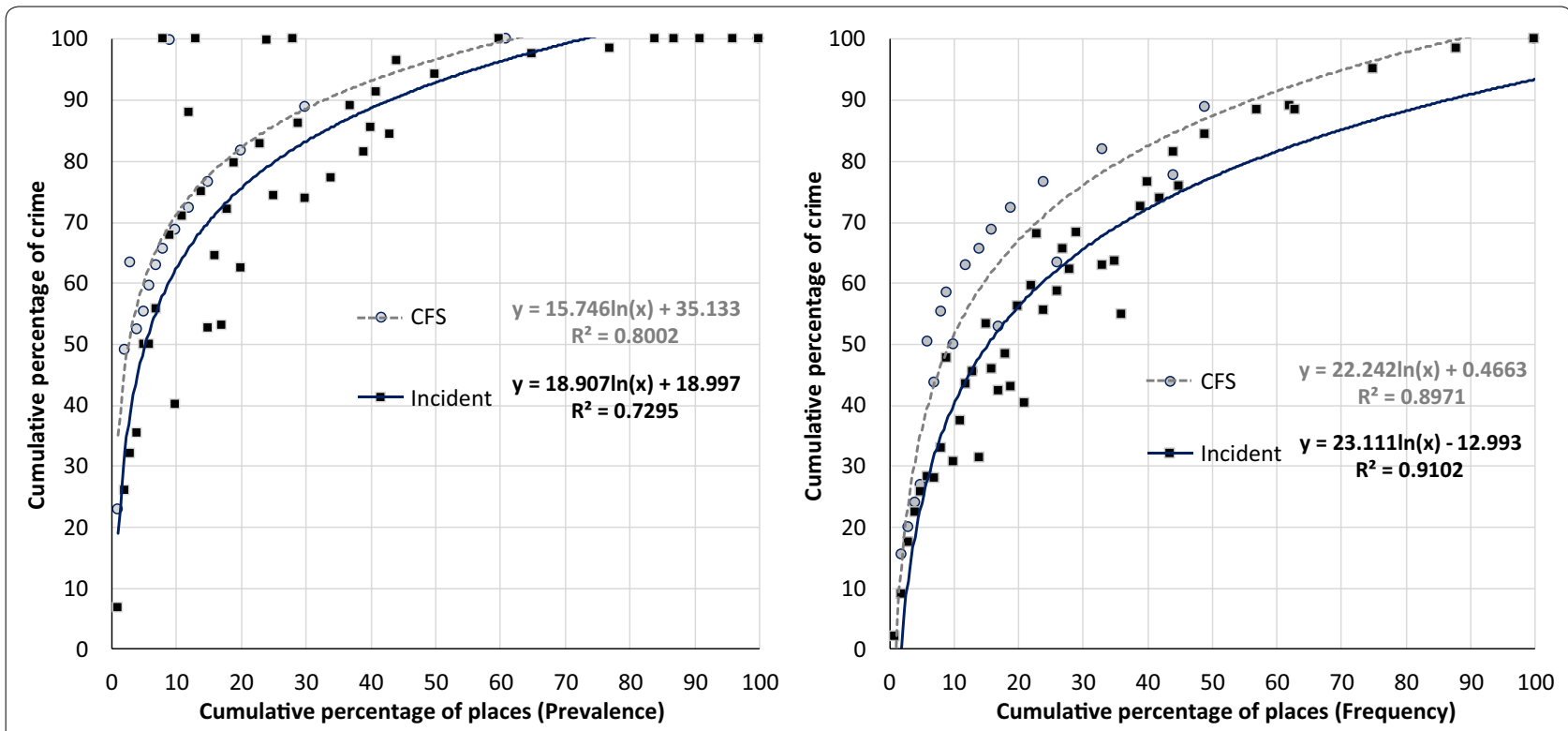

Fig. 3 Estimated distributions of crime at place between different measures of crime: CFS vs. incident

\section{Geographic unit of analysis}

The term "place" does not have a single definition, and has been operationalized in several ways: as an address, a household, a street segment, or even an area. ${ }^{15}$ Do these different interpretations of place influence crime concentration, or are they interchangeable?

Our database of studies contained varying numbers of studies using these different place units. We found 3 address studies (with $54 \mathrm{X}-\mathrm{Y}$ points), 8 household studies (with 127 points), 13 segment studies (with 196 points) and one area study (with $12 \mathrm{X}-\mathrm{Y}$ points). Figure 4 shows that as the size of the place unit declines (area to address and household) crime becomes more concentrated. If we look at the most crime afflicted $5 \%$ of the places, when one looks at household or address data one finds about $55 \%$ of the crime being accounted for. The worst $5 \%$ of the street segments, in contrast, account for around $42 \%$ of the crimes. And the worst $5 \%$ of the neighborhoods account for only around $20 \%$ of the crimes. These findings are consistent with the findings of Andresen et al. (2016), Johnson (2010), and Steenbeek and Weisburd (2016). And they are consistent with the fact that the bigger the area the more likely it will have at least one crime in any given time period (if you were to place a bet, you should put your money on any given household or address having no crime, but put your money on all neighborhoods having at least one crime in the time period of choice).

\footnotetext{
${ }^{15}$ We include 'area' because it was a place including both park area and 50 feet buffer zone surrounding the park. The areal size of this area is greater than street segment but much smaller than neighborhood or census tract.
}

When we look at the frequency curves (the single area study did not provide information we could use to estimate a frequency curve) we see that households display the least concentration and addresses the most, with segments in between. This suggests that given a first crime, addresses have a higher chance of a second or third event than do segments or households. This is interesting. But it might be due to the heterogeneity of addresses relative to households, and even segments. Address data contains a wide variety of different types of places-bar, school, shopping, worship, and other facilities-where household data contains only residential facilities. Businesses are more subject to repeat victimization than household (Bowers et al. 1998). Since many street segments will be mixed commercial residential, or completely commercial, segments may have more crimes than the more homogeneous households. The address studies also contain a heterogeneous set of places, thus increasing their concentration relative to households.

We do need to add this cautionary note. The address frequency concentration is higher than household frequency concentration (Fig. 4), even though both units seem to be similar conceptually. All of the household studies collected crime data based on survey method, while all of the address based studies used crimes reported to the police. One possible difference is that police address data might not distinguish among different households in the same apartment building, although survey data does. Another possible difference is that police data would be available for all apartments (flats) in a building, although sample surveys would only draw 

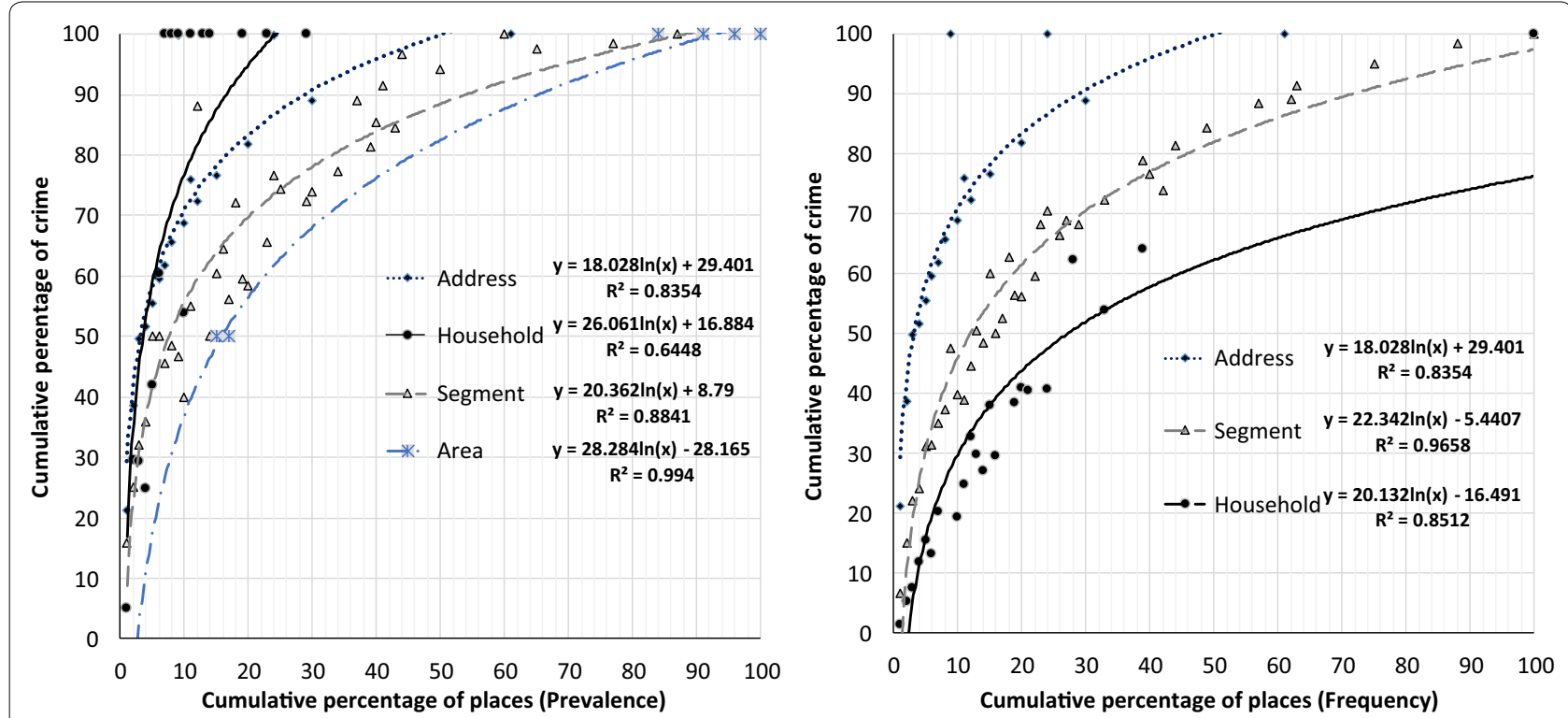

Fig. 4 Estimated distributions of crime at place among different geographic unit of analysis: address, household, segment, and area

data from a single household in the building. So even allowing for under reporting of crime in police data, survey data may underestimate crime concentration. This difference may hint at the possibly that the source of crime data could be a confounder in drawing conclusions from the concentration of crime studies. However, whether we combined address and household data or kept them separate, it is clear that crime is more concentrated at addresses than at street segments.

The fact that crime is more concentrated at the address level than the segment level for both frequency and prevalence is important. One reason is that, on a segment, many addresses will have no crimes. So, we confirm that a smaller unit of analysis is better able to pinpoint crime concentration (Weisburd et al. 2009a). This would account for the prevalence differences. The frequency differences suggest that it may not be just the large number of addresses with zero crimes inside segments with at least one crime that is producing the higher address concentration. It is quite possible that there are address level processes that more efficiently concentrate crime.

\section{Time period}

We also examined the change in the concentration of crime over time. We grouped the $\mathrm{X}-\mathrm{Y}$ points into three categories based on the year their study was published: before 1990, 1990 to 1999, and after 1999. We chose these three time periods because the decade of the 1990s encompassed a dramatic drop in reported crime (Eck and Maguire 2000; Farrell et al. 2011). Thus, we have a period before this drop, the period of the drop, and a period after the steep drop. For the prevalence curve, four studies provided $92 \mathrm{X}-\mathrm{Y}$ points for the period before 1990 , three studies provided $35 \mathrm{X}-\mathrm{Y}$ points for the period from 1990 to 1999 , and 19 studies provided $301 \mathrm{X}-\mathrm{Y}$ points for the period after 1999. The prevalence curves in Fig. 5 show less concentration of crimes in 2000s compared to two other periods. However, the prevalence curves for first two periods show that there is no significant difference in the concentration of crime at places. Specifically, the worst $10 \%$ of places for the first two periods account for about $75 \%$ of the crime, while the worst $10 \%$ of the places in the third period account for only $60 \%$ of crime. This finding suggests that there is a substantive difference in the crime trend after 1999 relative to two other periods: less concentration of crime at the same places in addition to crime drop around 1990s.

For the frequency curve, four studies provided $82 \mathrm{X}-\mathrm{Y}$ points for the first period, three studies provided $32 \mathrm{X}-\mathrm{Y}$ points for the second period, and 12 studies provided 196 $\mathrm{X}-\mathrm{Y}$ points for the third period. The second graph on the left in Fig. 5 shows no significant difference in the percentage of crime explained by the top $10 \%$ of the places across different time periods. We can better explain this by extrapolating the findings from the prevalence curve. The fact that crime is more dispersed across different places but the concentration did not change among the crime place after 1999 hint at the possibility that the probability of crime among crime places did not change over the decades of time period. 

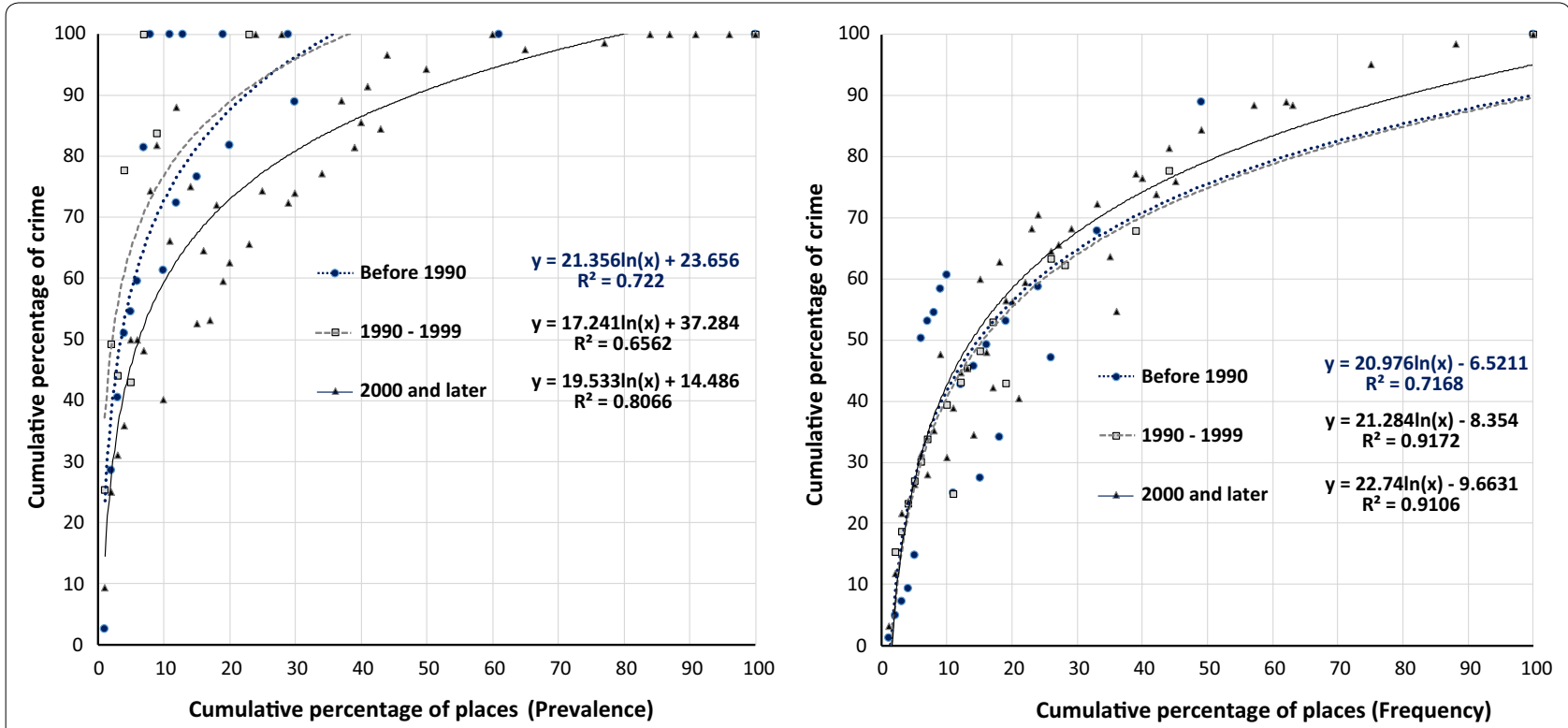

Fig. 5 Estimated distributions of crime at places across different time periods: before 1990, from 1990 to 1999, and after 1999

\section{U.S. vs. non-U.S}

We also examined the concentration of crime across different countries. Because the majority of the studies we reviewed used crime data from the United States, we dichotomized the studies as U.S. and non-U.S. For the prevalence curve, 17 U.S. studies provided $233 \mathrm{X}-\mathrm{Y}$ ordered pairs while nine non-U.S. studies provided 195 $\mathrm{X}-\mathrm{Y}$ ordered pairs. Non-U.S. studies were mostly from the United Kingdom, but there are two studies from Israel and Turkey. The prevalence graph in Fig. 6 shows that crime is more concentrated at a smaller proportion of places in the U.S. The worst $10 \%$ of places in the U.S. explained about $70 \%$ of crime whereas the same proportion accounted for about $58 \%$ of crime in non-U.S. studies. Though the difference between U.S. and non-U.S. seems substantive, and more crimes are likely to occur at the same place in U.S. compared to other countries, this does not mean that the U.S. is safer in general or that non-U.S. countries have a high prevalence of crime. We cannot make a defensible conclusion based on these findings without examining how these crime data were recorded (or collected), which crime types were measured, or determining which country's data among the non-U.S. countries primarily influenced this finding. Further, comparing the R-squared values for the U.S. and non-U.S. curves shows that there is more variation in U.S. crime concentration. The interpretation of these prevalence curves becomes clearer when we look at the frequency curves.

For the frequency curve, nine U.S. studies provided 124 $\mathrm{X}-\mathrm{Y}$ points and 10 non-U.S. studies provided $186 \mathrm{X}-\mathrm{Y}$ points. The second graph in Fig. 6 shows that there is no substantive difference in crime concentration between the U.S. and non-U.S. countries. The R-squared values for the U.S. and non-U.S. also show that both curves fit through the median points of each bin fairly well.

Findings from both prevalence and frequency curves are interesting. Even though the U.S. curves are based on crime data collected from a single country, these curves show more variation around the fitted lines compared to non-U.S. curves. Though we cannot provide a definitive answer for this, one possibility is that the variability across different states and cities in U.S. may have increased the variance among the $\mathrm{X}-\mathrm{Y}$ ordered pairs, and this may have further increased the variance of the median values of each bin.

\section{Type of crime (violent vs. property)}

Finally, we examine concentration for violent and property crime. Two graphs in Fig. 7 show how violent crime and property crime is concentrated at places. For estimating the prevalence curve, six studies provide $\mathrm{X}-\mathrm{Y}$ points for both violent (55 X-Y points) and property (82 $\mathrm{X}-\mathrm{Y}$ points) crime. Only one of these studies provides two violent and two property $\mathrm{X}-\mathrm{Y}$ points and five studies provide either violent (53 X-Y points) or property (80 $\mathrm{X}-\mathrm{Y}$ points) crime data, but not both. The figure shows that there is a significant difference in crime concentration between violent crime and property crime. When we look at the top $10 \%$ of the places, about $60 \%$ of violent crime was accounted for while over $70 \%$ of property crime was accounted for. This is an odd finding. There are 

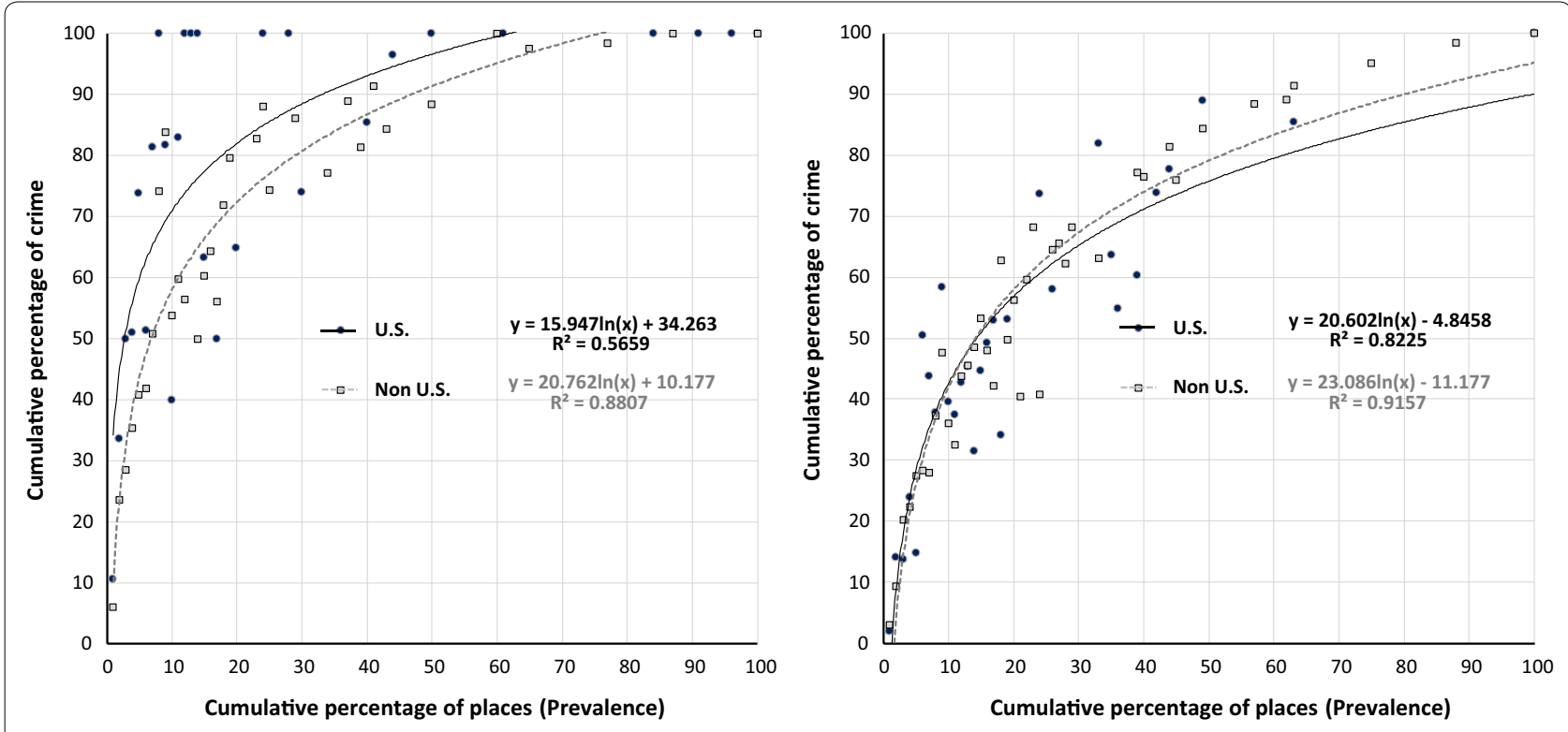

Fig. 6 Estimated distributions of crime at place between U.S. and non-U.S

many fewer violent crimes than property crimes. If these crimes were evenly distributed, fewer places would have violent crime than property crime (i.e., violent crime would be more concentrated). The differences between these two curves, therefore, cannot be due to the higher number places without property or without violent crimes. So for these results to be interpretable, violent crime should be less concentrated in frequency than property crime.

Unfortunately, this explanation is not substantiated when we look at the frequency curves: there is no meaningful difference in crime concentration between violent crime versus property crime. Four studies provide 25 violent crime $\mathrm{X}-\mathrm{Y}$ points while six studies provide 75 property crime points. Both logarithmic curves passing through the median values of each bin show almost the same marginal slope for every bin on the horizontal axis. It seems that the small discrepancy between these curves above $50 \%$ values on the horizontal axis is due to the properties of logarithmic function but not to a statistical difference. This leaves us with a puzzle we cannot solve with these data.

\section{Limitations}

The heterogeneity of the literature and the sheer scarcity of studies found for particular categories in place concentration studies led to a number of limitation that are important to bear in mind in interpreting our findings. Most of these limitations have been alluded to in the previous sections, but warrant reiteration here.
First, though we collected a comprehensive list of studies, we may have omitted some studies relevant to this line of research. This is because there are studies containing the relevant data, but describing place-crime concentration were not the studies' objectives. The concentration information in such studies was developed to aid the research, and it appears in tables and appendices, but the keywords we sought are not in the title, abstract, or text. Consequently, we cannot claim to have found the population of relevant studies. Therefore, our synthesis of these results should be regarded as suggestive rather than conclusive. Readers of this review study should keep this limitation in mind in interpreting the figures and tables.

Second, visual binning technique might reduce the true variation of $\mathrm{X}-\mathrm{Y}$ ordered pairs. Losing variations of the raw data points would reduce the degree of freedom, which would further lead to an incorrect estimation of the fitted line. Despite this potential limitation, we used a median of Ys for each bin to represent the typicality of the bin. Further, we did not find any alternative metric that could substitute this technique for aggregating $\mathrm{X}-\mathrm{Y}$ points for each bin.

Third, we did not weight our data nor $\mathrm{X}-\mathrm{Y}$ ordered pairs per study. However, as we did not find any substantial difference in the findings by weighting $\mathrm{X}-\mathrm{Y}$ pairs by study's sample size (see Appendix 1), we used the nonweighted data points for simplicity and parsimonious of our review study.

Fourth, we used the logarithmic function throughout the meta-analysis. Since we cannot log-transform zero 

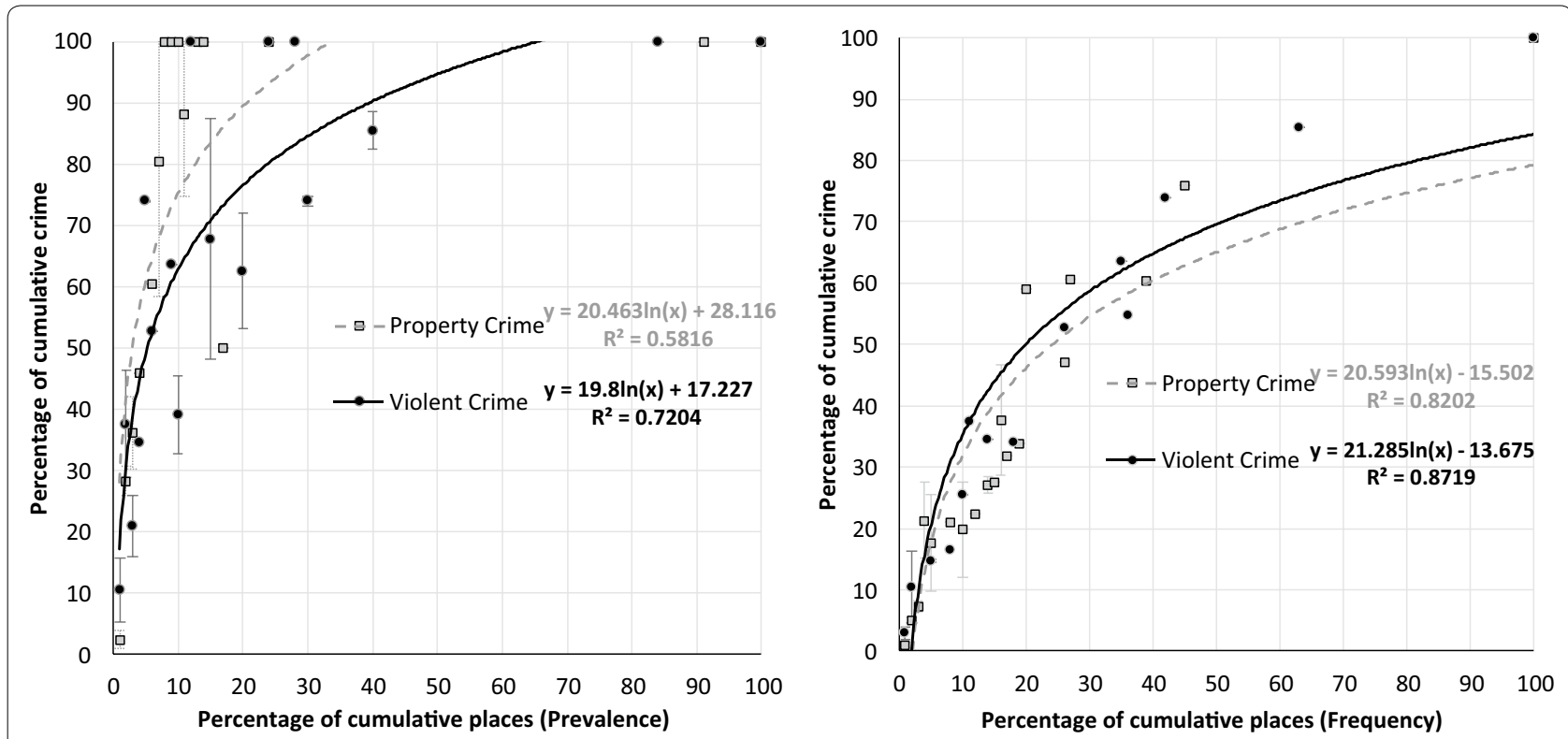

Fig. 7 Estimated distributions of crime at place between types of crime: violent crime vs. property crime

into an integer value, all curves in the figures are marginally away from the zero origin either vertically or horizontally. It is possible that different functions might apply to different categories of place concentration, rather than a simple log-transformed functional form fitting universally (e.g., violent crime fits one function while property crime fits another). However, we used a logarithmic function over all categories of place concentration because in this first effort to synthesize place studies, we wanted to keep comparisons simple. Further, we were interested in comparing concentration at places to concentration among offenders and victims (see Eck et al. in this issue) and we had no theoretical or other a priori reason to use different functional forms.

Last, findings in our review study are limited by the populations researcher have examined with sufficient frequency that we could make comparisons. For example, we could not compare specific crime type concentration at places, other than using the broad categories of violent and property crimes. Overtime, perhaps researchers will report detailed results that will allow more detailed comparisons.

\section{Discussion and conclusions}

Based on our review, there is no doubt that crime is concentrated at a small number of places regardless of how crime is measured, the geographic unit of analysis used, or type of crime. This conclusion is not surprising given previous research (Weisburd 2015). Though unsurprising, it is important, as this is the first systematic review and meta-analysis on the topic.
Although the concentration of crime at place is seemingly ubiquitous-we found no empirical study showing a lack of concentration-the amount of concentration varies. Some of this variation is due to measurement, unit of analysis, and crime type. And concentration varies depending on whether one is examining all places, regardless of crime experience (prevalence), or only those places with one or more crimes (frequency). However, the literature we have reviewed cannot fully support the conclusion that there is a precise law of concentration: a given percent of the worst afflicted places account for a fixed percent of the crime. Based on the estimated coefficients and intercepts of model specifications in this review study, the percent of crime explained by a specific percent of place (e.g., 5, 10, and 20\%) varies across various geographic units, crime types, and measures of crime (see Appendix 3). It is only when we aggregate all studies that we find evidence supporting a strong interpretation of Weisburd's (2015) law of crime concentration. A weaker version, that a relatively small proportion of all places contain most crime is supported.

If there is a "law" of concentration, it describes the general shape of the distribution-that a relatively small proportion places account for a relatively large proportion of crimes. Such a law would not guarantee, for example, that the most crime ridden $5 \%$ of the places contain any specific percent of crime, except that these places would have a lot more than $5 \%$. This is consistent with Hipp and Kim (2016) who reported that 5\% of street segments across 42 cities in southern California account for crime at its range from 35 to $100 \%$. 
Our findings that calls for services are more concentrated than crime incidents, and that property crime is more concentrated than violent crime (for prevalence) suggest that researchers should be careful about drawing conclusions from data aggregating diverse sets of crimes and places. There is a tension between the theoretical demand that specific types of crime be examined separately (at least until it has been demonstrated that they have the same pattern) and the pragmatic methods demands of examining a sufficiently large number of events that patterns can be detected. Large address-level multi-year datasets may help alleviate this tension, but they will not eliminate it. Perhaps the biggest advances will not come from more data, and not even from better statistical methods, but from deeper and more precise theories that explain crime concentration processes.

Our findings that crime is less concentrated at the top $10 \%$ of the worst places in 2000 s suggest that measures of crime preventions may have become more effective in reducing crime prone places compared to 1980s and 1990s. A cross-national comparison of crime concentration also suggests that United States may have suffered from high crime concentration compared to the places in other countries. However, due to the variability of cities and states in the United States, it is difficult to conclude that all places in U.S. cities and states have higher concentration of crime compared to Europe, Israel, and Turkey.

Our finding that address-level concentration of crime is higher than segment (or larger area) level concentration suggests that greater attention to site specific influences would be fruitful. Place management theory (Madensen and Eck 2013) provides a launching point for such an inquiry. This theory claims that the actions of property owners in their management capacity block crime or create opportunity structures for crime. Understanding how property owners react to crime thus becomes a central line of inquiry, in contrast to examining how people in an area invoke informal social controls, or fail to.

Our analysis of the crime at place literature also detected several anomalies that deserve further enquiry. First, though we would expect household data and address level data to be similar in concentration, they are not consistent in this regard. Household crime is more concentrated than address level data when looking at prevalence but less concentrated when looking at frequency. We offered a possible explanation, but this deserves more research. Second, property crime appears more concentrated than violent crime for prevalence, which is contrary to what we would expect. However, for frequency their relative concentrations appear similar.

These two curious findings may be due to the heterogeneity of the studies that we found. Place research is relatively new, and the studies of crime and place have followed a variety of lines of inquiry, using different data, from different cities, and applying different ways of examining their data. Though overall there are a large number of crime and place studies, when looking at subtypes (e.g., studies of segments vs. studies of addresses, or studies of property crime vs. studies pf violent crime) the number of studies for each type declines considerably. And due to vagaries in how crime-place distributions are reported, the number of $\mathrm{X}-\mathrm{Y}$ points varies. All of this suggests that summarizing this literature is problematic. Not only should more systematic reviews be conducted as more research becomes available, but future inquiries should examine other ways of summarizing these studies that could challenge our findings.

\section{Authors' contributions}

This paper was conducted by a team. YL was the lead writer for this paper, was the lead analyst, and provided expertise on places. JEE headed the team and provided overall guidance and editorial assistance. SO and NNM provided expertise on offenders and victims (respectively), assisted in the development of the research methods, and provided editorial reviews. All authors read and approved the final manuscript.

\section{Author details \\ ${ }^{1}$ School of Public Affairs, University of Colorado, Colorado Springs, CO 80918, USA. ${ }^{2}$ School of Criminal Justice, University of Cincinnati, Cincinnati, $\mathrm{OH}$ 45221, USA.}

\section{Acknowledgements}

To be added at the end of the review process.

\section{Competing interests}

The authors declare that they have no competing interests. We are not even sure readers have an interest in this research.

\section{Availability of data and materials}

Articles used in the systematic review are noted in the references. For other information regarding data, please contact the lead author.

\section{Ethics approval and consent to participate}

Does not apply. As a review of summary data from previously conducted research, no humans (or their tissues) participated as subjects in this research. 


\section{Appendices}

Appendix 1: Estimated distributions of crime at place for prevalence and frequency schema: A comparison of fitted lines between un-weighted and weighted $X-Y$ points
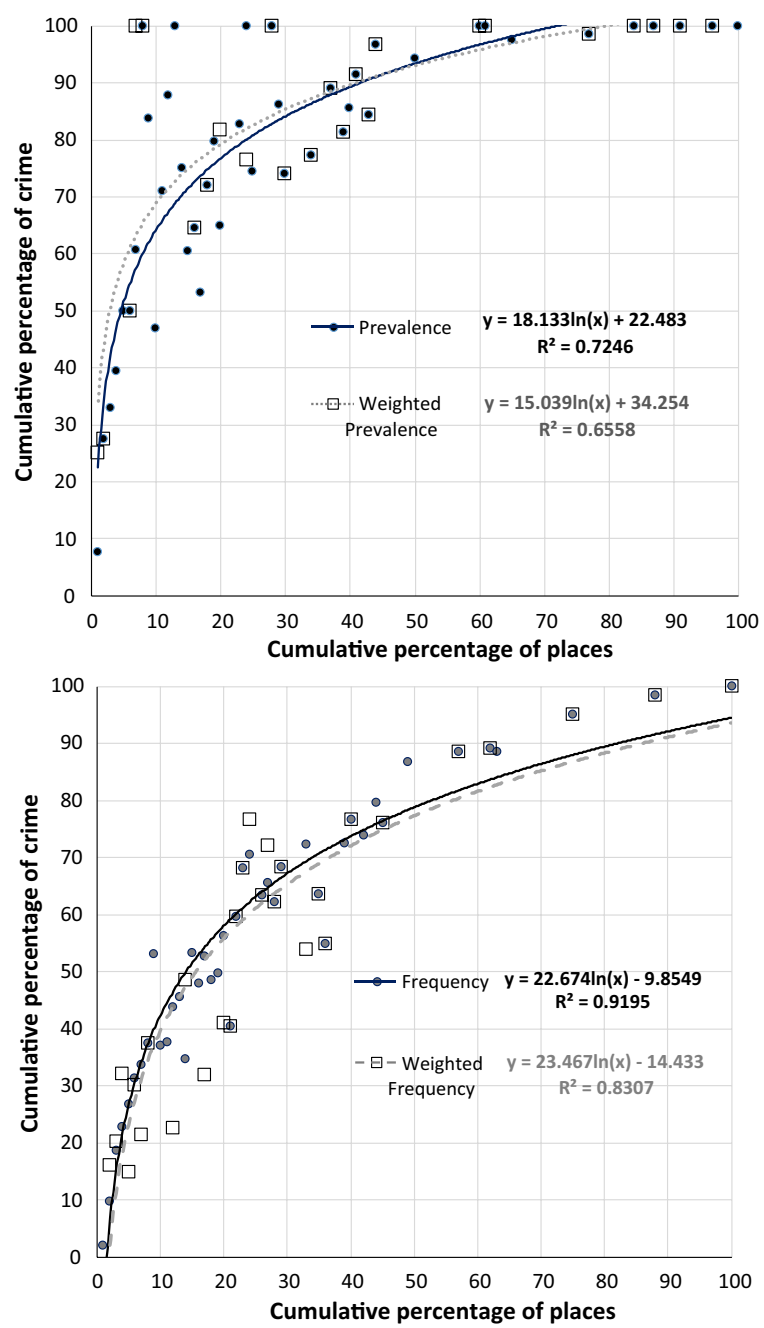

Appendix 2: A mathematical note addressing possible measurement error problem by using CFS as a measures of crime

Suppose a researcher is interested in the correlation between crime and certain dependent variable (y), using CFS as a proxy to crime. We can express the reduced model as follows:

$$
y=\beta_{0}+\beta 1 \text { CFS }+\mu
$$

We can rewrite this as:

$$
y=\beta_{0}+\beta_{1} \text { CFS }+\left(\mu-\beta_{1} \mathrm{e}\right),
$$

where e (measurement error) $=$ crime - CFS

Under the assumption that $\operatorname{Cov}($ crime, $\mu)=$ $\operatorname{Cov}($ crime, $y)=0$,

$$
\operatorname{plim}\left(\hat{\beta}_{1}\right)=\frac{\operatorname{Cov}(\text { crime }, y)}{\operatorname{Var}(\text { crime })}=\beta_{1}-\beta_{1} \frac{\operatorname{Cov}(\text { crime }, e)}{\operatorname{Var}(\text { crime })}=\beta_{1}
$$

However, if any variable (here, for example, fear of crime) inside the error term (e) is correlated with the proxy (here, CFS), then

$\operatorname{Cov}($ crime, e $)=\operatorname{Cov}(\operatorname{CFS}+\mathrm{e}, \mathrm{e})=\operatorname{Cov}(\mathrm{CFS}, \mathrm{e})+\operatorname{Var}(\mathrm{e})$

Because the covariance between CFS and error term is no longer i.i.d., the numerator in the equation (a) will not cancel out to 0 , thus estimated beta $\left(\hat{\beta}_{1}\right)$ will be always biased or inconsistent. With this possible problem in mind, we should be cautious at using CFS as an appropriate proxy to crime in research.

Appendix 3: Estimated coefficients and summary statistics of the models specifications in Figs. 2, 3, 4, 5, 6 and 7 


\begin{tabular}{|c|c|c|c|c|c|c|c|c|c|c|c|c|c|}
\hline \multirow[t]{2}{*}{ Figure Number } & \multirow[t]{2}{*}{ Key } & \multirow{2}{*}{$\begin{array}{l}\text { Number } \\
\text { of } \\
\text { Studies }\end{array}$} & \multirow{2}{*}{$\begin{array}{l}\text { Number } \\
\text { of }(X, Y) \\
\text { Points }\end{array}$} & \multirow{2}{*}{ Constant } & \multirow[t]{2}{*}{ Beta } & \multirow[t]{2}{*}{ Std. error } & \multicolumn{2}{|c|}{$\begin{array}{l}\text { Confidence } \\
\text { interval }\end{array}$} & \multirow[t]{2}{*}{ t-statistic } & \multicolumn{4}{|c|}{$\begin{array}{l}\text { Percentage of crime } \\
\text { explained by }\end{array}$} \\
\hline & & & & & & & & & & $5 \%$ & $10 \%$ & $20 \%$ & $50 \%$ \\
\hline \multirow[t]{2}{*}{ Figure 2} & Prevalence & 26 & 428 & 22.48 & 18.13 & 1.75 & 14.64 & 21.63 & 10.39 & 51.7 & 64.2 & 76.8 & 93.4 \\
\hline & Frequency & 19 & 310 & -9.86 & 22.67 & 1.05 & 20.58 & 24.77 & 21.63 & 26.6 & 42.4 & 58.1 & 78.8 \\
\hline \multirow[t]{4}{*}{ Figure 3} & CFS (P) & 2 & 35 & 35.13 & 15.75 & 2.10 & 11.54 & 19.95 & 7.49 & 60.5 & 71.4 & 82.3 & 96.7 \\
\hline & Incident (P) & 24 & 393 & 19.00 & 18.91 & 1.82 & 15.27 & 22.55 & 10.39 & 49.4 & 62.5 & 75.6 & 93.0 \\
\hline & CFS (F) & 2 & 33 & 0.47 & 22.24 & 1.73 & 18.79 & 25.70 & 12.87 & 36.3 & 51.7 & 67.1 & 87.5 \\
\hline & Incident (F) & 17 & 277 & -12.99 & 23.11 & 1.13 & 20.84 & 25.38 & 20.38 & 24.2 & 40.2 & 56.2 & 77.4 \\
\hline \multirow[t]{7}{*}{ Figure 4} & Address (P) & 3 & 54 & 29.40 & 18.03 & 2.00 & 14.03 & 22.03 & 9.01 & 58.4 & 70.9 & 83.4 & 99.9 \\
\hline & Household (P) & 8 & 127 & 16.88 & 26.06 & 4.99 & 16.07 & 36.05 & 5.22 & 58.8 & 76.9 & 95.0 & 100.0 \\
\hline & Segment $(P)$ & 13 & 196 & 8.79 & 20.36 & 1.25 & 17.87 & 22.85 & 16.34 & 41.6 & 55.7 & 69.8 & 88.4 \\
\hline & Area $(P)$ & 1 & 12 & -28.17 & 28.28 & 1.10 & 26.09 & 30.48 & 25.74 & 17.4 & 37.0 & 56.6 & 82.5 \\
\hline & Address (F) & 3 & 49 & 1.17 & 21.09 & 1.66 & 17.77 & 24.41 & 12.71 & 35.1 & 49.7 & 64.3 & 83.7 \\
\hline & Segment (F) & 9 & 119 & -5.44 & 22.34 & 0.70 & 20.94 & 23.74 & 31.86 & 30.5 & 46.0 & 61.5 & 82.0 \\
\hline & Household (F) & 5 & 105 & -16.49 & 20.13 & 1.88 & 16.37 & 23.90 & 10.69 & 15.9 & 29.9 & 43.8 & 62.3 \\
\hline \multirow[t]{6}{*}{ Figure 5} & Before $1990(P)$ & 4 & 92 & 23.66 & 21.36 & 3.21 & 14.93 & 27.78 & 6.65 & 58.0 & 72.8 & 87.6 & 100.0 \\
\hline & 1990 to 1999 (P) & 3 & 35 & 37.28 & 17.24 & 4.72 & 7.81 & 26.68 & 3.66 & 65.0 & 77.0 & 88.9 & 100.0 \\
\hline & 2000 and later $(P)$ & 19 & 301 & 14.49 & 19.53 & 1.53 & 16.47 & 22.60 & 12.75 & 45.9 & 59.5 & 73.0 & 90.9 \\
\hline & Before $1990(F)$ & 4 & 82 & -6.52 & 20.98 & 2.95 & 15.08 & 26.87 & 7.12 & 27.2 & 41.8 & 56.3 & 75.5 \\
\hline & 1990 to $1999(\mathrm{~F})$ & 3 & 32 & -8.35 & 21.28 & 1.60 & 18.09 & 24.48 & 13.31 & 25.9 & 40.7 & 55.4 & 74.9 \\
\hline & 2000 and later (F) & 12 & 196 & -9.66 & 22.74 & 1.13 & 20.49 & 24.99 & 20.18 & 26.9 & 42.7 & 58.5 & 79.3 \\
\hline \multirow[t]{4}{*}{ Figure 6} & U.S. (P) & 17 & 233 & 34.26 & 15.95 & 2.74 & 10.47 & 21.43 & 5.82 & 59.9 & 71.0 & 82.0 & 96.6 \\
\hline & Non-U.S. (P) & 9 & 195 & 10.18 & 20.76 & 1.37 & 18.02 & 23.51 & 15.13 & 43.6 & 58.0 & 72.4 & 91.4 \\
\hline & U.S. (F) & 9 & 124 & -4.85 & 20.60 & 1.81 & 16.98 & 24.22 & 11.39 & 28.3 & 42.6 & 56.9 & 75.7 \\
\hline & Non-U.S. (F) & 10 & 186 & -11.18 & 23.09 & 1.14 & 20.81 & 25.36 & 20.32 & 26.0 & 42.0 & 58.0 & 79.1 \\
\hline \multirow[t]{4}{*}{ Figure 7} & Violent (P) & 6 & 55 & 17.23 & 19.80 & 3.19 & 13.43 & 26.17 & 6.22 & 49.1 & 62.8 & 76.5 & 94.7 \\
\hline & Property (P) & 6 & 82 & 28.12 & 20.463 & 4.64 & 11.19 & 29.74 & 4.41 & 61.0 & 75.2 & 89.4 & 100.0 \\
\hline & Violent (F) & 4 & 25 & -13.68 & 21.285 & 2.36 & 16.58 & 26.00 & 9.04 & 20.6 & 35.3 & 50.1 & 69.6 \\
\hline & Property (F) & 6 & 75 & -15.50 & 20.593 & 2.34 & 15.92 & 25.27 & 8.81 & 17.6 & 31.9 & 46.2 & 65.1 \\
\hline
\end{tabular}

\section{Publisher's Note}

Springer Nature remains neutral with regard to jurisdictional claims in published maps and institutional affiliations.

Received: 17 February 2017 Accepted: 16 May 2017

Published online: 26 May 2017

\section{References}

'Denotes a study we identified through keyword search. * Denotes a study included in both the systematic review and meta-analysis

Andresen, M. A. (2006). A spatial analysis of crime in Vancouver, British Columbia: A synthesis of social disorganization and routine activity theory. The Canadian Geographer, 50(4), 487-502.

Andresen, M. A., Linning, S. J., \& Malleson, N. (2017). Crime at places and spatial concentrations: Exploring the spatial stability of property crime in Vancouver BC, 2003-2013. Journal of Quantitative Criminology, 33, 255. doi:10.1007/s10940-016-9295-8.

Bowers, K. J., Hirschfield, A., \& Johnson, S. D. (1998). Victimization revisited: A case study of non-residential repeat burglary on Merseyside. British Journal of Criminology, 38(3), 429-452.

Braga, A. A. (2001). The effects of hot spots policing on crime. The ANNALS of the American Academy of Political and Social Science, 578(1), 104-125.
Braga, A. A. (2005). Hot spots policing and crime prevention: A systematic review of randomized controlled trials. Journal of experimental crimino-ogy, 1(3), 317-342.

${ }^{*}$ Braga, A. A., Hureau, D. M., \& Papachristos, A. V. (2011). The relevance of micro places to citywide robbery trends: A longitudinal analysis of robbery incidents at street corners and block faces in Boston. Journal of Research in Crime and Delinquency, 48(1), 7-32.

Braga, A. A., Papachristos, A. V., \& Hureau, D. M. (2010). The concentration and stability of gun violence at micro places in Boston, 1980-2008. Journal of Quantitative Criminology, 26(1), 33-53.

${ }^{*}$ Braga, A. A., Papachristos, A. V., \& Hureau, D. M. (2014). The effects of hot spots policing on crime: An updated systematic review and meta-analysis. Justice Quarterly, 31(4), 633-663.

${ }^{*}$ Braga, A. A., \& Schnell, C. (2013). Evaluating place-based policing strategies lessons learned from the smart policing initiative in Boston. Police Quarterly, 16(3), 339-357.

${ }^{\dagger}$ Braga, A. A., Weisburd, D. L., Waring, E. J., Mazerolle, L. G., Spelman, W., \& Gajewski, F. (1999). Problem-oriented policing in violent crime places: A randomized controlled experiment. Criminology, 37(3), 541-580.

${ }^{\dagger}$ Chainey, S., Tompson, L., \& Uhlig, S. (2008). The utility of hotspot mapping for predicting spatial patterns of crime. Security Journal, 21(1), 4-28.

Christenson, B. (2013). Assessing foreclosure and crime at street segments in Mecklenburg County, North Carolina (Doctoral dissertation), Southern Illinois University, Carbondale. 
${ }^{*}$ Dario, L. M., Morrow, W. J., Wooditch, A., \& Vickovic, S. G. (2015). The point break effect: an examination of surf, crime, and transitory opportunities. Criminal Justice Studies, 28(3), 257-279.

${ }^{*}$ Duru, H. (2010). Crime on Turkish streetblocks: an examination of the effects of high-schools, on-premise alcohol outlets, and coffeehouses (Doctoral dissertation), University of Cincinnati, Cincinnati.

${ }^{\dagger}$ Eck, J. E., Clarke, R. V., \& Guerette, R. T. (2007). Risky facilities: Crime concentration in homogeneous sets of establishments and facilities. In G. Farrell, K. J. Bowers, S. D. Johnson, \& M. Townsley (Eds.), Imagination for crime prevention: Essays in honour of ken pease (Vol. 21, pp. 225-264). Monsey, NY: Criminal Justice Press.

Eck, J. E., Lee, Y. J., SooHyun, O., \& Martinez, N. N. (2016). Compared to what? Estimating the relative concentration of crime at places using systematic and other reviews.

Eck, J. E., \& Maguire, E. R. (2000). Have changes in policing reduced violent crime? An assessment of the evidence. In A. Blumstein \& J. Wallman (Eds.), The crime drop in America (pp. 207-265). Cambridge University Press, Cambridge.

Farrell, G., Tseloni, A., Mailley, J., \& Tilley, N. (2011). The crime drop and the security hypothesis. Journal of Research in Crime and Delinquency, 48(2), $147-175$.

Farrington, D. P. (2015). Cross-national comparative research on criminal careers, risk factors, crime and punishment. European Journal of Criminology, 12(4), 386-399.

${ }^{\dagger}$ Frank, R., Brantingham, P. L., \& Farrell, G. (2012). Estimating the true rate of repeat victimization from police recorded crime data: A study of burglary in metro Vancouver 1. Canadian Journal of Criminology and Criminal Justice/La Revue canadienne de criminologie et de justice pénale, 54(4), 481-494.

${ }^{\dagger}$ Gorr, W. L., \& Lee, Y. (2015). Early warning system for temporary crime hot spots. Journal of Quantitative Criminology, 31(1), 25-47.

${ }^{*}$ Groff, E., \& McCord, E. S. (2012). The role of neighborhood parks as crime generators. Security Journal, 25(1), 1-24.

Higgins, J. P., \& Green, S. (2011). Cochrane handbook for systematic reviews of interventions: Version 5.1.0 (updated March 2011). The Cochrane Collaboration. Retrieved from http://www.cochrane-handbook.org.

* ${ }^{\dagger}$ Hindelang, M. J., Gottfredson, M. R., \& Garofalo, J. (1978). Victims of personal crime: An empirical foundation for a theory of personal victimization. Cambridge, MA: Ballinger.

Hipp, J. R., \& Kim, Y. A. (2016). Measuring crime concentration across cities of varying sizes: Complications based on the spatial and temporal scale employed. Journal of Quantitative Criminology. doi:10.1007/ s10940-016-9328-3.

${ }^{+}$Homel, R., \& Clark, J. (1994). The prediction and prevention of violence in pubs and clubs. Crime Prevention Studies, 3, 1-46.

${ }^{\dagger}$ Hope, T. (1985), Implementing crime prevention measures, Home Office Research Study No. 86. London: Home Office.

Hope, T. (1995). The flux of victimization. British Journal of Criminology, 35(3), 327-342.

${ }^{*}{ }^{\dagger}$ Johnson, S. D. (2008). Repeat burglary victimisation: A tale of two theories. Journal of Experimental Criminology, 4(3), 215-240.

Johnson, S. D. (2010). A brief history of the analysis of crime concentration. European Journal of Applied Mathematics, 21(4-5), 349-370.

${ }^{\dagger}$ Kennedy, D. M., Braga, A. A., \& Piehl, A. M. (1997). The (un) known universe: Mapping gangs and gang violence in Boston. In D. Weisburd \& T. McEwen (Eds.), Crime Mapping and Crime Prevention.

* ${ }^{\dagger}$ Kennedy, L. W., Caplan, J. M., \& Piza, E. (2011). Risk clusters, hotspots, and spatial intelligence: risk terrain modeling as an algorithm for police resource allocation strategies. Journal of Quantitative Criminology, 27(3), 339-362.

* ${ }^{\dagger}$ Lee, Y. J. \& Eck, J. E. (2014) Analysis of crime concentration at street segment level, Cincinnati 2009, doi:10.13140/RG.2.2.17172.91521.

${ }^{*}{ }^{\dagger}$ Lloyd, S., Farrell, G., \& Pease, K. (1994). Preventing repeated domestic violence: A demonstration project on Merseyside. London: Home Office Police Research Group.

†Loukaitou-Sideris, A. (1999). Hot spots of bus stop crime: The importance of environmental attributes. Journal of the American Planning Association 65(4), 395-411.

Lum, C. (2003). The spatial relationship between street-level drug activity and violence. (Doctoral dissertation), University of Maryland, College Park.
${ }^{*}$ Madensen, T. D., \& Eck, J. E. (2008). Violence in bars: Exploring the impact of place manager decision-making. Crime Prevention and Community Safety, 10(2), 111-125.

Madensen, T. D., \& Eck, J. E. (2013). Crime places and place management. In F. T. Cullen \& P. Wilcox (Eds.), The Oxford handbook of criminological theory (pp. 554-578). New York, NY: Oxford University Press.

Martinez, N. N., Lee, Y. J., Eck J. E., \& SooHyun O. (2016). Ravenous wolves revisited: A systematic review of offending concentration.

McGill, R., Tukey, J. W., \& Larsen, W. A. (1978). Variations of box plots. The American Statistician, 32(1), 12-16.

${ }^{\dagger}$ Morenoff, J. D., Sampson, R. J., \& Raudenbush, S. W. (2001). Neighborhood inequality, collective efficacy, and the spatial dynamics of urban violence. Criminology, 39(3), 517-558.

Mulrow, C. D., \& Oxman, A. (1997). How to conduct a cochrane systematic review: Version 3.0.2. San Antonio: The Cochrane Collaboration.

${ }^{*}$ Nelson, J. F. (1980). Multiple victimization in american cities-A statistical analysis of rare events. American Journal of Sociology, 85(4), 870-891.

Newman, M. E. (2005). Power laws, Pareto distributions and Zipf's law. Contemporary Physics, 46(5), 323-351.

Osborn, D. R., \& Tseloni, A. (1998). The distribution of household property crimes. Journal of Quantitative Criminology, 14(3), 307-330.

${ }^{\dagger}$ Pease, K., \& Laycock, G. (1999). Revictimization, reducing the heat on hot victims (pp. 1-6). Canberra: Australian Institute of Criminology.

${ }^{*}$ Percy, S. L. (1980). Response time and citizen evaluation of police. Journal of Police Science and Administration, 8(1), 75-86.

Phillips, C., \& Brown, D. (1998). Perspectives on policing: Synopsis of recent research. Policing: An International Journal of Police Strategies Management, 21(3), 562-568.

${ }^{\dagger}$ Ratcliffe, J. H., Taniguchi, T., Groff, E. R., \& Wood, J. D. (2011). The Philadelphia foot patrol experiment: A randomized controlled trial of police patrol effectiveness in violent crime hotspots. Criminology, 49(3), 795-831.

${ }^{\dagger}$ Rephann, T. J. (2009). Rental housing and crime: the role of property ownership and management. The Annals of Regional Science, 43(2), 435-451.

Rocque, M., Posick, C., Marshall, I. H., \& Piquero, A. R. (2015). A comparative, cross-cultural criminal career analysis. European Journal of Criminology, 12(4), 40.

${ }^{\dagger}$ Schmid, C. F. (1960). Urban Crime Areas: Part II. American Sociological Review, 25(5), 655-678.

Sherman, L. W. (1995). Hot spots of crime and criminal careers of places. In J. E. Eck \& D. Weisburd (Eds.), Crime and place, crime prevention studies (Vol. 4, pp. 35-52). Monsey, NY: Criminal Justice Press.

*'Sherman, L. W., Gartin, P. R., \& Buerger, M. E. (1989). Hot spots of predatory crime: Routine activities and the criminology of place. Criminology, 27(1), 27-56.

*'Sherman, L. W., Schmidt, J. D., Rogan, D., \& DeRiso, C. (1991). Predicting domestic homicide: Prior police contact and gun threats. In M. Steinman (Ed.), Woman battering: Policy responses (pp. 73-93). Newport: Academy of Criminal Justice Sciences, Northern Kentucky University.

*'Sidebottom, A. (2012). Repeat burglary victimization in Malawi and the influence of housing type and area-level affluence. Security Journal, 25(3), 265-281.

†Sidebottom, A., \& Bowers, K. (2010). Bag theft in bars: An analysis of relative risk, perceived risk and modus operandi. Security Journal, 23(3), 206-224.

SooHyun, O., Martinez, N. N., Lee, Y. J., \& Eck, J. E. (2016). How concentrated is crime among victims? A systematic review from 1977 to 2014.

†Spelman, W. (1995). Criminal careers of public places. In J. E. Eck \& D. Weisburd (Eds.), Crime and place, crime prevention studies (Vol. 4, pp. 115-144). Monsey, NY: Criminal Justice Press.

Spelman, W., \& Eck, J. E. (1989). Sitting ducks, ravenous wolves and helping hands: new approaches to urban policing. Austin, TX: Lyndon B. Johnson School of Public Affairs, University of Texas at Austin.

Steenbeek, W., \& Weisburd, D. (2016). Where the action is in crime? An examination of variability of crime across different spatial units in the Hague, 2001-2009. Journal of Quantitative Criminology, 32(3), 449-469.

Tillman, R. (1987). The size of the "criminal population": the prevalence and incidence of adult arrest. Criminology, 25(3), 561-580.

*tTownsley, M., Homel, R., \& Chaseling, J. (2000). Repeat burglary victimisation: Spatial and temporal patterns. Australian \& New Zealand Journal of Criminology, 33(1), 37-63. 
Trickett, A., Ellingworth, D., Hope, T., \& Pease, K. (1995). Crime victimization in the eighties: changes in area and regional inequality. British Journal of Criminology, 35(3), 343-359.

Trickett, A., Osborn, D. R., Seymour, J., \& Pease, K. (1992). What is different about high crime areas? British Journal of Criminology, 32(1), 81-89.

${ }^{*}$ Tseloni, A., Wittebrood, K., Farrell, G., \& Pease, K. (2004). Burglary victimization in England and Wales, the United States and the Netherlands: A crossnational comparative test of routine activities and lifestyle theories. British Journal of Criminology, 44(1), 66-91.

${ }^{*}{ }^{\dagger}$ Webb, B. (1994). Tackling repeat victimization: Getting it right. In National board for crime prevention regional conferences.

${ }^{*}$ Weisburd, D. (2015). The law of crime concentration and the criminology of place. Criminology, 53(2), 133-157.

*'Weisburd, D., \& Amram, S. (2014). The law of concentrations of crime at place: the case of Tel Aviv-Jaffa. Police Practice and Research, 15(2), 101-114.

Weisburd, D., Bernasco, W., \& Bruinsma, G. (Eds.). (2009a). Putting crime in its place: Units of analysis in geographic criminology. New York: Springer.
*†'Weisburd, D., Bushway, S., Lum, C., \& Yang, S.-M. (2004). Trajectories of crime at places: A Longitudinal study of street segments in the city of Seattle. Criminology, 42(2), 283-321.

${ }^{*}$ Weisburd, D. L., Groff, E., \& Morris, N. (2011). Hot spots of juvenile crime: Findings from Seattle. Washington, District of Columbia: National Institute of Justice.

tWeisburd, D., Groff, E. R., \& Yang, S. M. (2014). Understanding and controlling hot spots of crime: The importance of formal and informal social controls. Prevention Science, 15(1), 31-43.

${ }^{*}$ Weisburd, D., Morris, N. A., \& Groff, E. R. (2009b). Hot spots of juvenile crime: A longitudinal study of arrest incidents at street segments in Seattle, Washington. Journal of Quantitative Criminology, 25(4), 443-467.

Weisburd, D., Wyckoff, L. A., Ready, J., Eck, J. E., Hinkle, J. C., \& Gajewski, F. (2006). Does crime just move around the corner? A controlled study of spatial displacement and diffusion of crime control benefits. Criminology, 44(3), 549-592.

Wilcox, P., \& Eck, J. E. (2011). Criminology of the unpopular. Criminology and Public Policy, 10(2), 473-482

\section{Submit your manuscript to a SpringerOpen ${ }^{\circ}$ journal and benefit from:}

- Convenient online submission

- Rigorous peer review

- Immediate publication on acceptance

- Open access: articles freely available online

- High visibility within the field

- Retaining the copyright to your article

Submit your next manuscript at springeropen.com 